\title{
EFFECTS OF HYSTERETIC MODEL ON SEISMIC DEMANDS: CONSIDERATION OF NEAR-FAULT GROUND MOTIONS
}

\author{
CHIN-HSIUNG LOH $^{1 *}$, SHIUAN WAN ${ }^{2}$ AND WEN-I LIAO ${ }^{2}$ \\ ${ }^{I}$ Department of Civil Engineering, National Taiwan University, and National Center for Research on Earthquake \\ Engineering, Taipei, Taiwan. \\ ${ }^{2}$ National Center for Research on Earthquake Engineering, Taipei, Taiwan.
}

\begin{abstract}
SUMMARY
This paper summarizes the results of a study that is to evaluate the structural response attributes of near-fault ground motion. Ground motion recordings from the Chi-Chi earthquake are used as inputs to the structural system. An improved nonlinear hysteretic model, based on the experimental study, was used to calculate the response of the single degree-of-freedom inelastic system. Comparison of the results of analysis with traditional elasticperfect plastic mode calculations was made. Discussions on the inelastic design spectrum, particularly the codespecified base shear coefficients, using the improved nonlinear hysteretic model incorporated with the near-fault input ground motion are made. Copyright (C) 2002 John Wiley \& Sons, Ltd.
\end{abstract}

\section{INTRODUCTION}

Near-fault (or near-field) ground motion shows two important characteristics: a permanent displacement offset along the fault and a pulse-like velocity waveform, which have caused severe damage of civil infrastructures in recent major earthquakes - Northridge in 1994, Kobe in 1995 and Chi-Chi in 1999. Particularly for the Chi-Chi (Taiwan) earthquake a lot of near-fault ground motion records were obtained (Loh et al., 2000). This pulse-like motion is believed to be potentially destructive to structures. The study of near-fault ground-motion characteristics and implementation of the seismic design code are a very important topic both to the seismological and to the engineering communities.

Several important efforts have been pointed out in previous studies. Bertero, Mahin and Herrera (1978) analysed fixed-base buildings subjected to ground shaking and showed that the near-field ground motions with pulses can induce higher responses. Anderson and Bertero (1987) studied the correlation between the width of the acceleration pulse and the natural period of the structure. They pointed out if the width of the pulse is larger than the natural period of the structure, the structure may be damaged much more. Iwan (1997) stated that there are rather distinct low-frequency pulses in the acceleration time histories that will result in coherent pulses in the velocity and displacement time histories. For structures subjected to such ground motion, these pulses will propagate through the structure as waves, and the response spectrum analysis may not capture the effect of these pulses. Iwan also proposed a series of spectra for near-field ground motions. Malhotra (1999) studied the response characteristics of near-field pulse-like ground motions. He shown that ground motions with a high Peak Ground Acceleration (PGA) to Peak Ground Velocity (PGV) ratio have a wide acceleration-

* Correspondence to: C. Loh, National Center for Research on Earthquake Engineering, 200, Sec. 3, Hsinhai Road, Taipei, Tawain, Republic of China. E-mail: lohc@ncree.gov.tw 


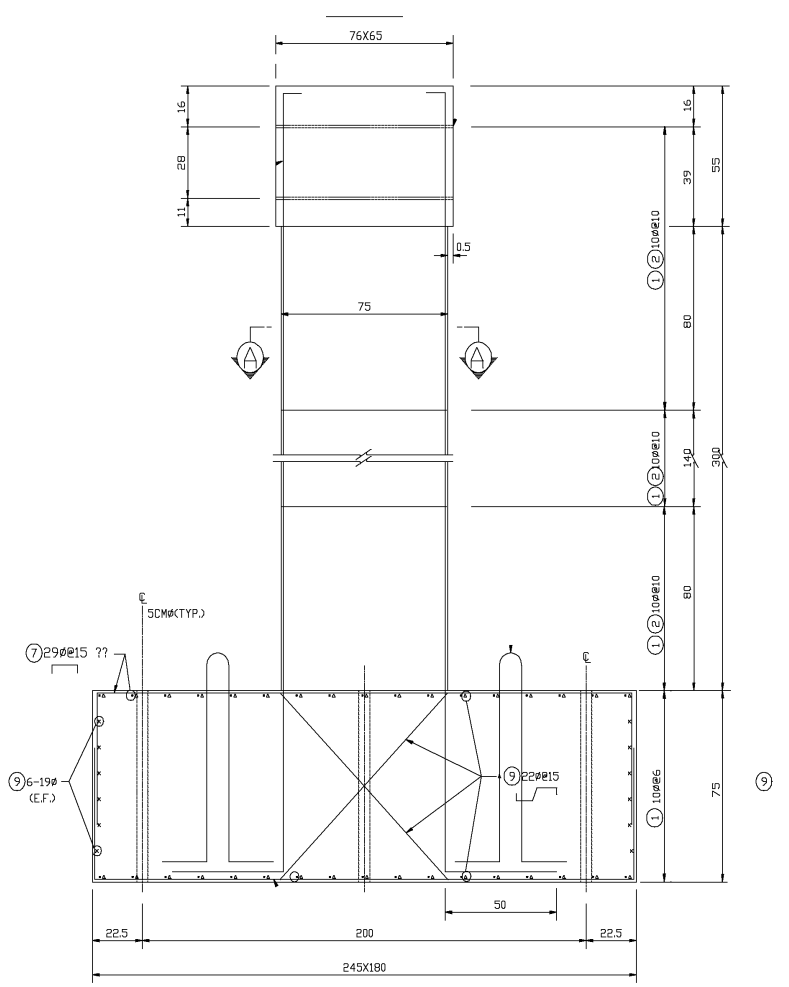

Figure 1. Experimental setup of bridge column BMR1

sensitive region in their response spectrum. This phenomenum will increase the base shear, interstorey drift and ductility demand of the high-rise buildings. Chai and Loh (1999) studied the linear response of a hinge-supported bridge subjected both to the simulated near-fault ground motion and the Landers earthquake recorded at the Lucern Valley site. Three types of velocity pulses are used to determine the strength reduction factor of structures with different periods. Alavi and Krawinkler (2000) used the moment magnitude and epicentre distance combined with pulse-strength demand spectra to evaluate the base strength by considering a constant ductility. Makris and Chang (2000) studied the effect of near-fault ground motion on seismic-isolated structures. They also proposed an equivalent pulse to predict the response features of near-fault ground motion.

In this study, a nonlinear single degree-of-freedom (SDOF) system was developed based on the experimental study. With the developed model through the analysis on the inelastic response spectrum the code-specified base-shear coefficient of an SDOF system (Taiwan bridge design code) is discussed.

\section{DEVELOPMENT OF NONLINEAR HYSTERETIC MODEL}

Modeling the hysteretic behaviour of structural elements is one of the core aspects in nonlinear structural analysis. An experimental study on the capacity of a reinforced-concrete bridge column, conducted at the National Center for Research on Earthquake Engineering (NCREE), is incorporated in this study. Experimental investigations on the reinforced-concrete bridge column have been carried out to study the seismic performance of existing bridges in Taiwan. Figure 1 illustrates the details of 
Bridge column 1 BMR 1

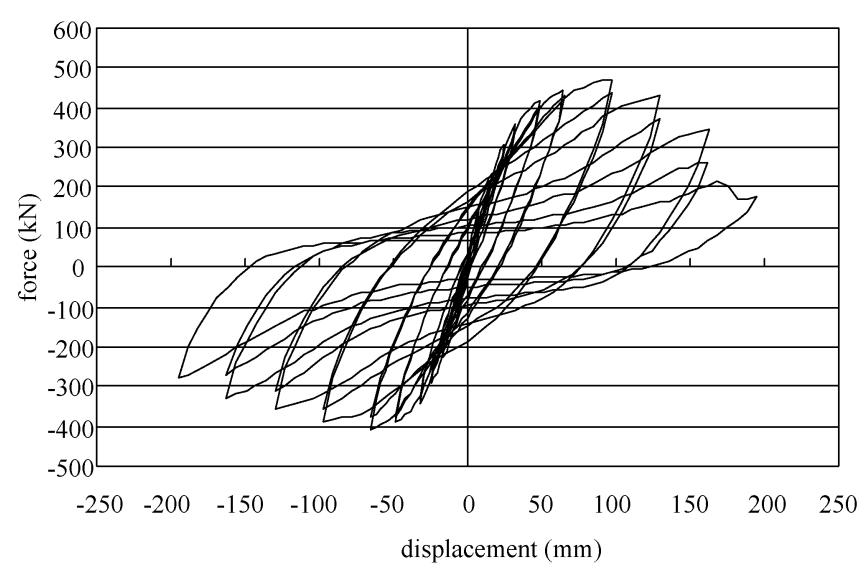

Figure 2. Hysteretic loop of specimen BMR1 under a cyclic loading test

the benchmark bridge column profile. The cross-section of the rectangular bridge column is $75 \mathrm{~cm}$ by $60 \mathrm{~cm}$, and the cross-section of the circular column is $76 \mathrm{~cm}$ in diameter.

BMR1 is a rectangular bridge column that is designed according to the 1995 version of Taiwan bridge design code. The longitudinal reinforcement consists of 32 No. 6 bars throughout the height of

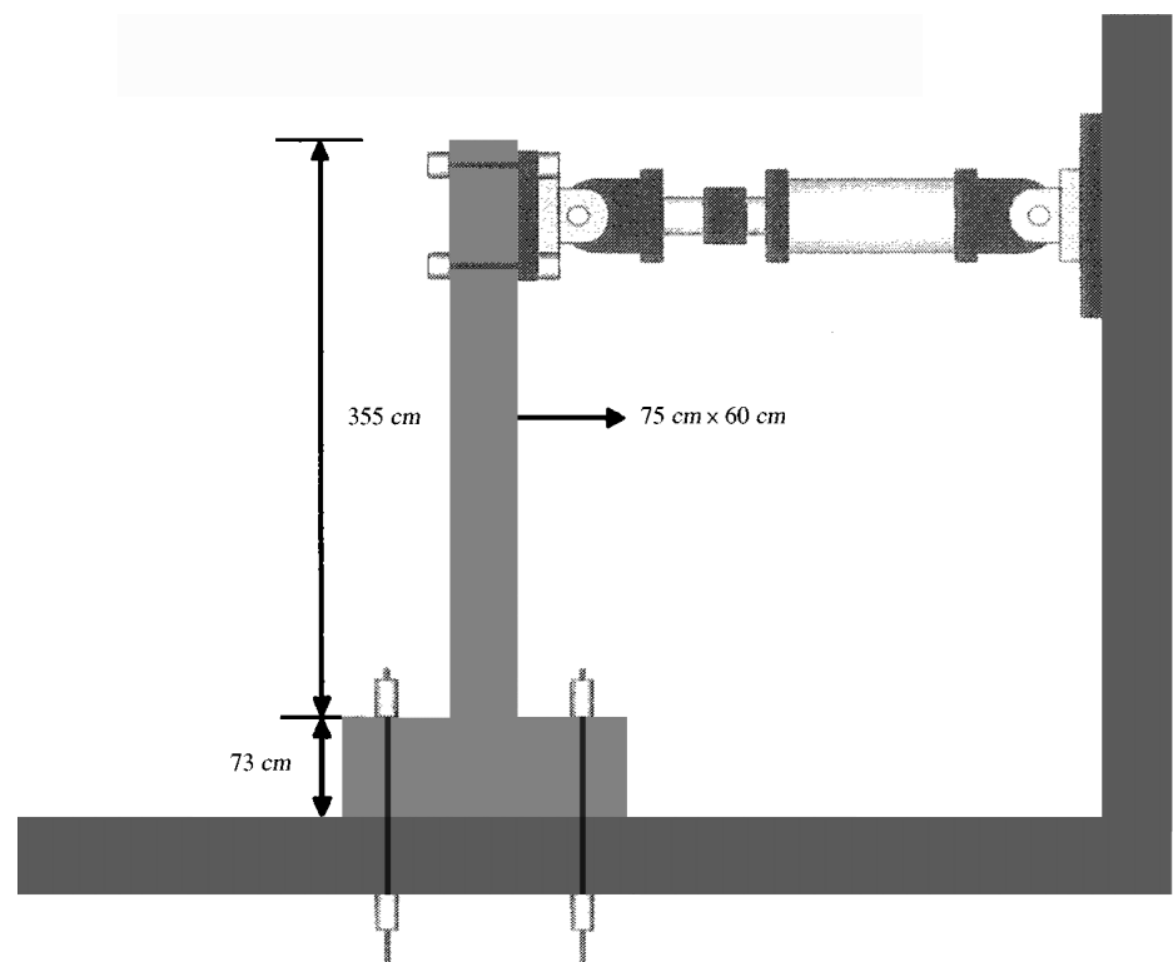

Figure 3. The pseudo-dynamic experimental setup of bridge column BMR1 


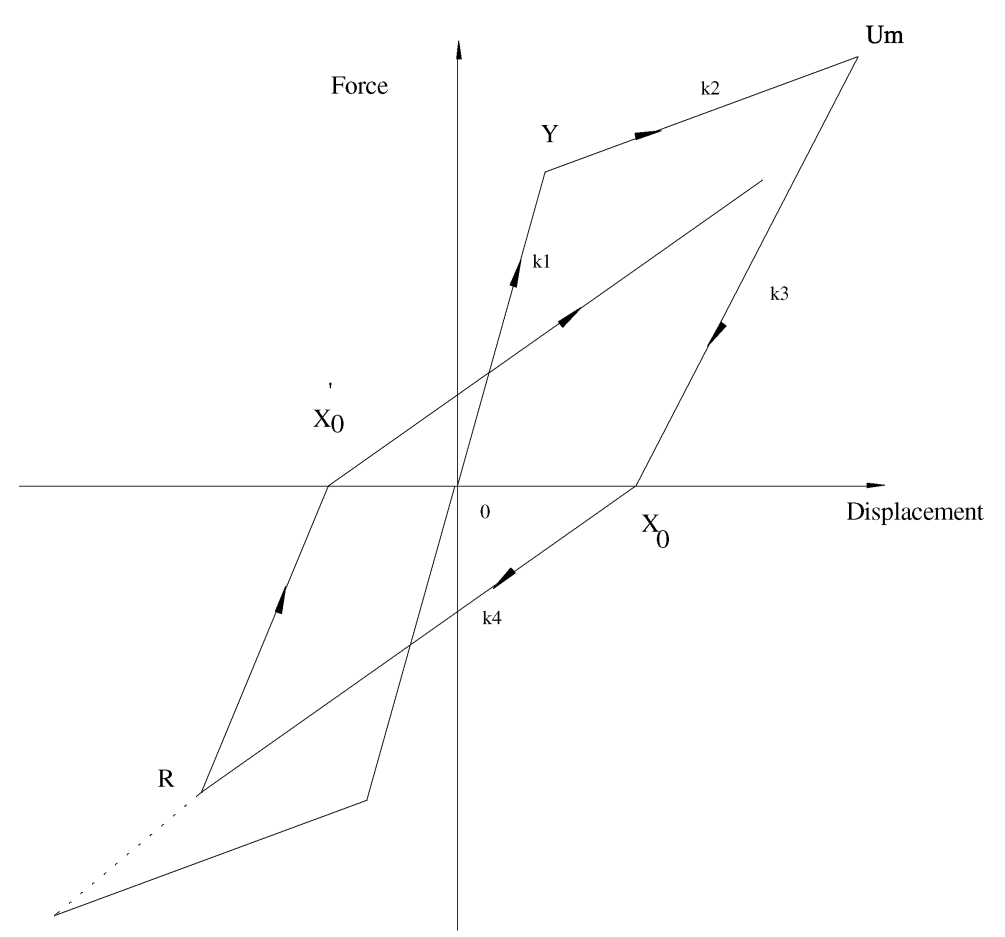

Figure 4. The Q-Hyst force-displacement model of a reinforced concrete column (source: Takeda, 1979)

the column. The shear reinforcement consists of No. 3 stirrups spaced at $10 \mathrm{~cm}$ with $135^{\circ}$ and $90^{\circ}$ at the two ends. In the laboratory, the bridge column hysteretic behaviour was tested by a cyclic loading test to observe the hysteretic behaviour and the capacity of the column. The results of the test on hysteretic behaviour is drawn in Figure 2. A pseudo-dynamic test was also performed with a specified input ground motion to investigate the dynamic behaviour of the bridge column BMR1. Figure 3 presents the overall experimental setup.

To establish a mathematical model that may represent the nonlinear hysteretic behaviour of the system, the Q-Hyst model proposed by Takeda (1970) and Priestley et al. (1993) was used to fit the results of the experimental study. The Q-Hyst model is illustrated in Figure 4. The rules of the Q-Hyst model loop can be expressed as:

- elastic loading and unloading, use slope $0 Y$;

- plastic loading and unloading:

- plastic loading, use slope $Y U_{\mathrm{m}}$;

- plastic unloading, use slope $U_{\mathrm{m}} X_{0}$;

- cyclic loading:

- if loading or unloading on slope $U_{\mathrm{m}} X_{0}$, heep using $U_{\mathrm{m}} X_{0}$;

- if loading on slope $X_{0} R$, heep using $X_{0} R$;

- if unloading on slope $X_{0} R$, use $X_{0}^{\prime} R$.

To determine the model parameters of the Takeda model from the experimental data, a computer program was developed based on experimental results (Wan 1999). A series of stiffnesses, $k_{1}, k_{2}, k_{3}$ 


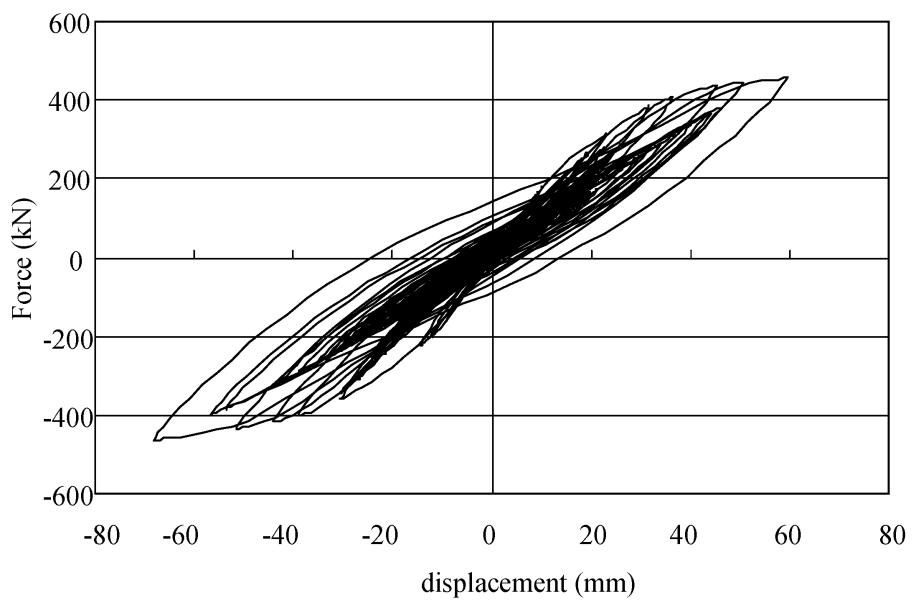

Figure 5. Force-displacement diagram of BMR1 column from pseudo-dynamic experimental test using ground motion input at station Tcu075

and $k_{4}$, were generated from the experimental results in the cyclic loading test as mentioned in Figure 2. The equations were found as

$$
\begin{aligned}
& k_{1}=k(1-2 \cdot 46 \theta) \\
& k_{2}=k(0 \cdot 143-1 \cdot 33 \theta) \\
& k_{3}=k\left(0 \cdot 1702-0 \cdot 036 \mu-0 \cdot 0012 \mu^{2}+0 \cdot 64 \theta\right) \\
& k_{4}=k\left(1 \cdot 022-0 \cdot 136 \mu-0.0037 \mu^{2}-1 \cdot 82 \theta\right)
\end{aligned}
$$

where $\mu$ is the ductility factor. The stiffnesses $k_{1}, k_{2}, k_{3}$ and $k_{4}$ are shown in Figure 4 . The parameter $k$ represents the initial elastic stiffness. The parameter $\theta$ is the stability coefficient, which can be expressed as

$$
\theta=\frac{P}{k L}
$$

where

$$
\mathrm{P}=0 \cdot 1 A_{\mathrm{g}} f_{\mathrm{c}}^{\prime}
$$

The parameter $A_{\mathrm{g}}$ is the gross section area of concrete, $f_{\mathrm{c}}^{\prime}=210 \mathrm{~kg} \mathrm{~cm}^{-2}$ and $L$ is the height of the specimen.

\section{MODEL VERIFICATION}

As part of this study, a computer program based on the Takeda (1970) model with hysteretic rules mentioned in Figure 4 was used to analyse the structural response. To verify the proposed hysteretic model comparison of the numerical and experimental displacement time history was made. The Takeda model incorporated with the identified model parameters from experimental results of the hysteretic loop of the column was selected as a nonlinear restoring force term of a SDOF system. The system was 


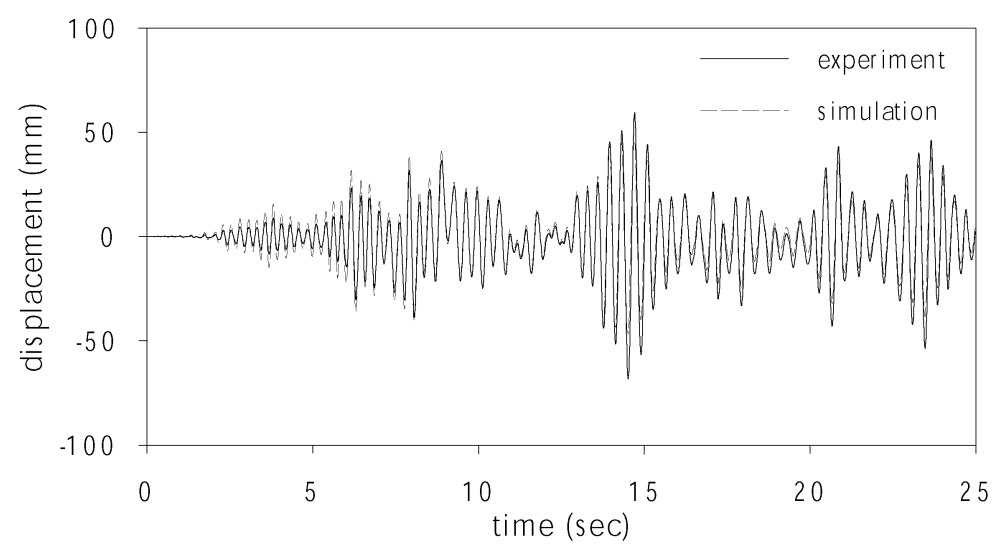

Figure 6. Comparison of the displacement-time history at the top of the column from the pseudo-dynamic experiment and the computer simulation (station Tcu075 normalized to $0.8 \mathrm{~g}$ )

subjected to the input ground motion collected from the station Tcu075 (20-45 s, Chi-Chi earthquake data normalized to $0.8 \mathrm{~g}$ ). Figure 5 shows the force-displacement diagram of the benchmark column from the pseudo-dynamic test. Results from numerical simulation of the benchmark column with the same input motion was also used for comparison. Figure 6 illustrates the comparison of the displacement-time history between the pseudo-dynamic experiment and the computer model. Figure 7 illustrates the comparison of the time history analysis of the force component between the pseudodynamic experiment and the numerical result of the proposed nonlinear model.

From previous discussion about the numerical simulation and the experimental study, it is believed that the proposed improved hysteretic model is precise enough to predict the structural response of a column subjected to earthquake excitation. It has to be pointed out that a damping ratio of $1.2 \%$ is presumed in the pseudo-dynamic experimental implementation and may induce a slight experimental error.

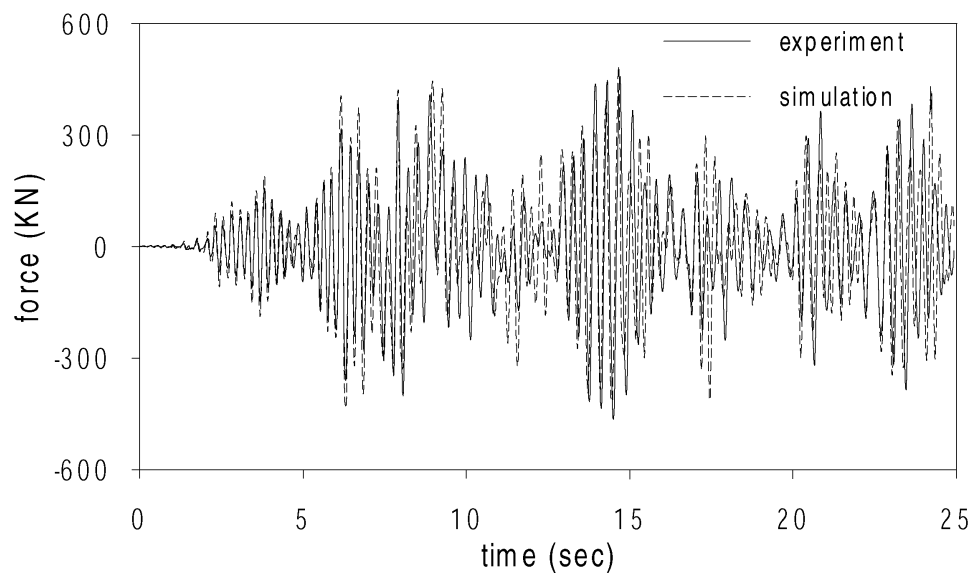

Figure 7. Comparison of force-time history for the pseudo-dynamic experiment and the computer simulation (station Tcu075 normalized to $0.8 \mathrm{~g}$ ) 


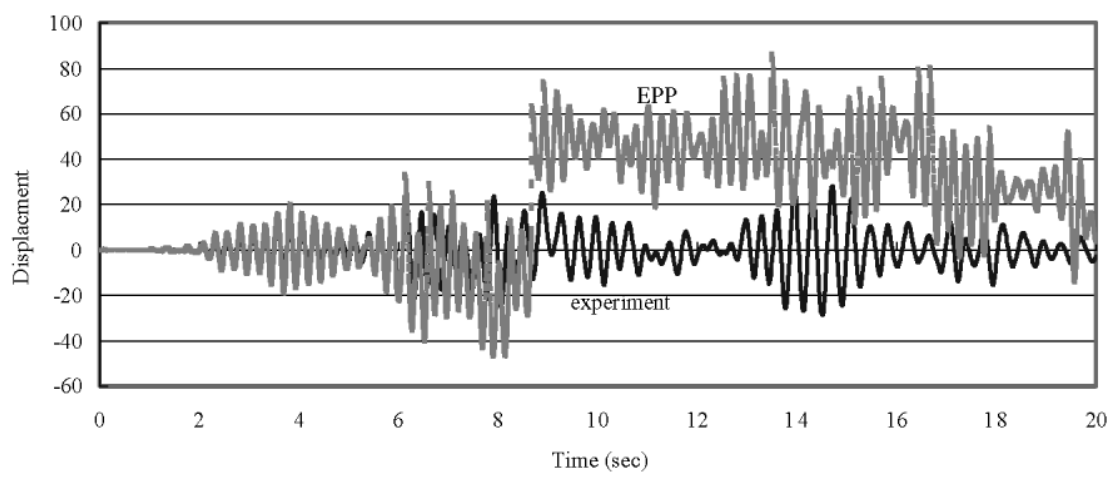

Figure 8. Differences in the estimation of displacement of a single-degree-of-freedom nonlinear system by using the elastic-perfect-plastic model and the proposed model (force in the $y$ direction, $F_{y}=404 \mathrm{kN}$; period $T=0.25 \mathrm{~s}$; input is from station Tcu075, normalized to $0 \cdot 8 \mathrm{~g}$ )

Different from the proposed nonlinear hysteretic model a commonly used inelastic model is the elastic-perfect-plastic model (EPP model). Normally, the code-specified reduction factor is generated from inelastic response spectrum analysis by using elastic-perfect-plastic model. However, if the model cannot truly reflect the structural behaviour, the estimated structural response will deviate from the true system response when subjected to an earthquake excitation. Figure 8 presents the displacement discrepancy of a SDOF nonlinear system calculated by using either the EPP -model or the proposed nonlinear hysteretic model when subjected to earthquake excitation collected from station Tcu075 (normalized to $0 \cdot 8 \mathrm{~g}$ ).

It can be concluded that the proposed inelastic model (modified Takeda model) can predict the response which is similar to the results from the pseudo-dynamic experiment whereas the EPP model cannot. Since the near-fault ground motion was used as the input motion, and since the characteristics of a near-fault earthquake present a pulse-like velocity wave which will cause a permanent displacement if the EPP model was used, the permanent displacement will cause permanent displacement in the numerical simulation which is not so obvious in the experimental verification. Therefore, in this study the proposed modified Takeda model was used which provides more accurate results than the EPP model in the analysis of the inelastic response spectrum subjected to both nearfault and far-field earthquake motion.

\section{DISCUSSION ON SEISMIC DESIGN CODE}

The bridge seismic design code of the column base shear $V$ for the Taiwan area is expressed as

$$
V=\frac{Z I}{\Omega \alpha_{y}}\left(\frac{C}{F_{u}}\right) W
$$

where $Z$ is the designed PGA value with 475 years return period, $C$ is the elastic design spectrum, $\Omega$, equal to 1.4 , is the over strength factor, $\alpha_{y}$ is the structure-related factor, $F_{u}$ is the reduction factor, and $C / F_{u}$ can be defined as the base shear coefficient. The parameter $W$ represents the total weight of the 
Table 1. Observed Stations

\begin{tabular}{|c|c|c|}
\hline Category & Area & Station \\
\hline 1 & Taipei basin (soft soil deposit) & $\begin{array}{l}\text { Tap001, Tap003, Tap006, Tap007, Tap008, Tap010, Tap012, } \\
\text { Tap013, Tap017, Tap021 }\end{array}$ \\
\hline 2 & Taipei basin (hard soil deposit) & $\begin{array}{l}\text { Tap028, Tap032, Tap034, Tap042, Tap047, Тар049, Tap051, } \\
\text { Tap053, Tap072, Tap078 }\end{array}$ \\
\hline 3 & Taichung county* & Tcu052, Tcu068, Tcu075, Tcu102 \\
\hline 4 & Taichung county $\dagger$ & Tcu065, Tcu072, Tcu084, Tcu129 \\
\hline 5 & Chia-Yi plain & Chy024, Chy029, Chy035, Chy036 \\
\hline
\end{tabular}

* PGV/PGA $>0 \cdot 2$

$\dagger \mathrm{PGV} / \mathrm{PGA}<0 \cdot 2$.

structure. The parameter $I$ represents the importance factor $(I=1)$. The design shear force $V_{\mathrm{d}}$ can then be defined as

$$
V_{\mathrm{d}}=\frac{Z I C W}{1 \cdot 4 \alpha_{y} F_{u}}
$$

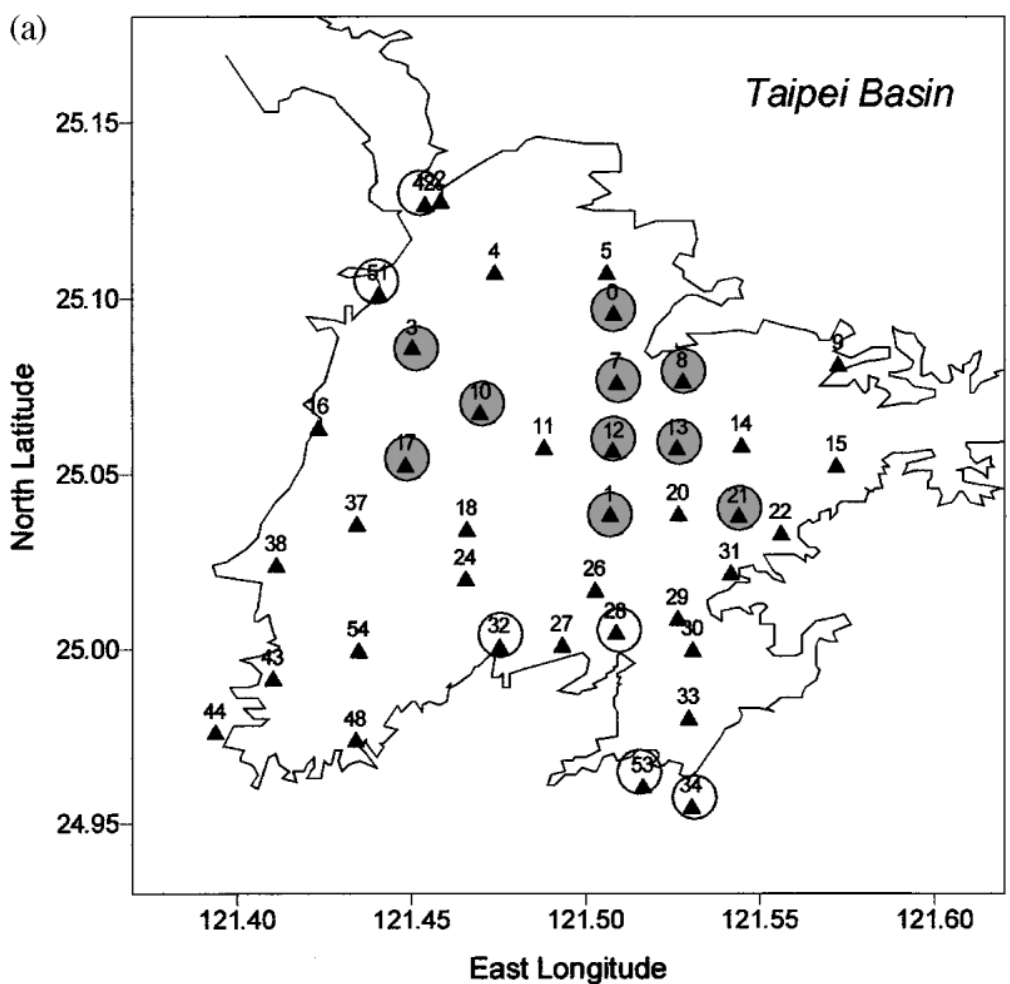

Soft site condition

Hard site condition

Figure 9. Strong motion instrumentation: (a) in the Tapei Basin (stations are represented by numbered triangles); (b) along the Chelungpu fault (open circles, stations in the Taichung area; triangles, stations in the Chai-I area) 


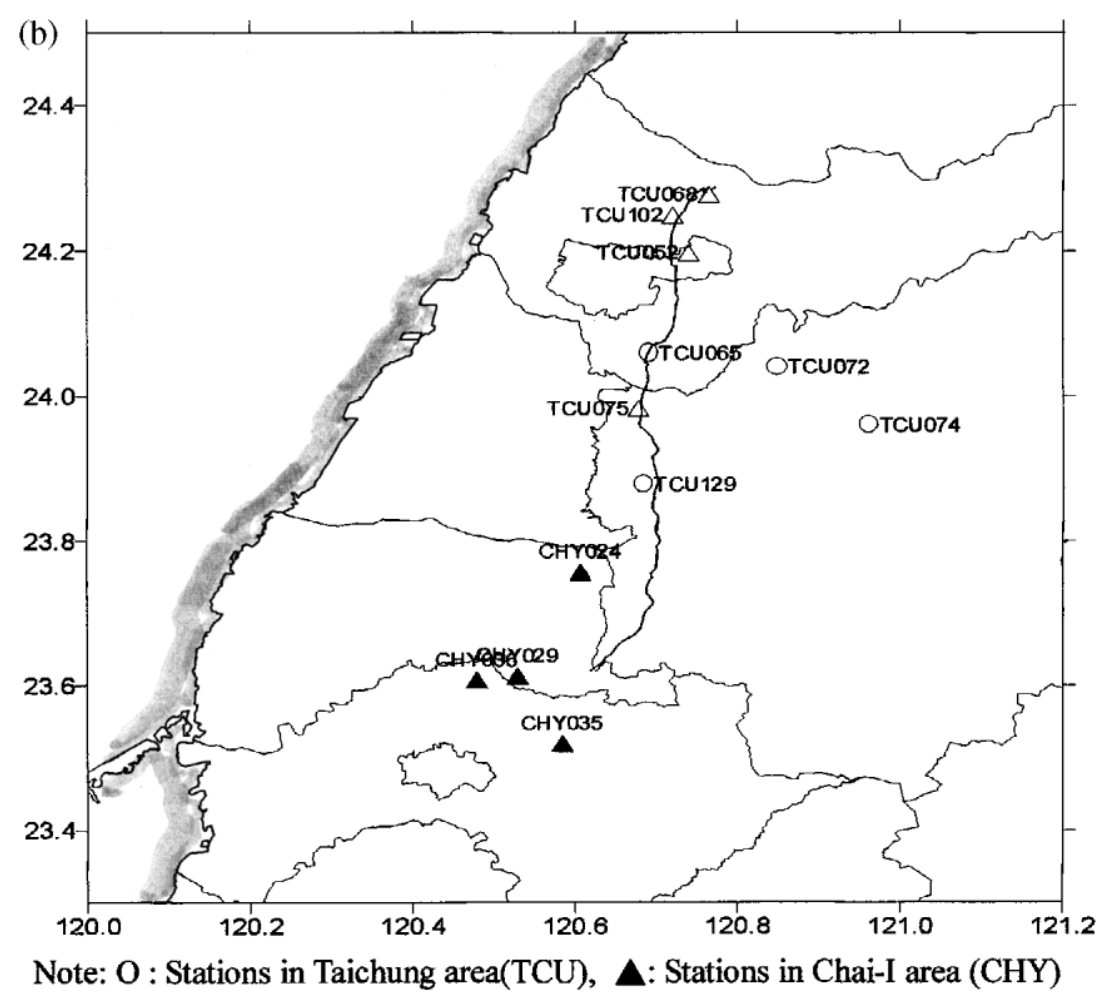

Figure 9. Continued

The yield shear force can be written as

$$
V_{\mathrm{y}}=1 \cdot 4 \alpha_{y} V_{\mathrm{d}}
$$

Therefore, the base shear coefficient (BSC) is defined as

$$
\frac{C}{F_{u}}=\frac{F_{y}}{W \times(P G A)}
$$

On 21 September 1999 an earthquake with a local magnitude of $7 \cdot 3$ struck the centre district of Taiwan and resulted in a tremendous disaster. Strong ground motion data collected from this earthquake will be used as input motion for the study of inelastic response spectrum. Table 1 lists the name of the station where data were collected in this study. Five categories of station were selected. Figures 9(a) and 9(b) show the location of the strong ground motion instrument in Taipei and in TaiChung, including the Chia-I area, respectively.

Category 1 and Category 2 represent the hard and soft soil deposit of the Taipei Basin, respectively. From past studies it can be concluded that the ratio of PGV to PGA is a dominant factor to identify the effect of near-fault ground motion. Therefore, data collected from stations near Taichung county which are close to the Chelungpu fault can be separated into two different categories (category 3 and category 4) with a PGV to PGA ratio greater than and less than $0 \cdot 2$, respectively. The Chia-I plain (category 5 ) is also considered another category of strong ground motion data for the analysis. 


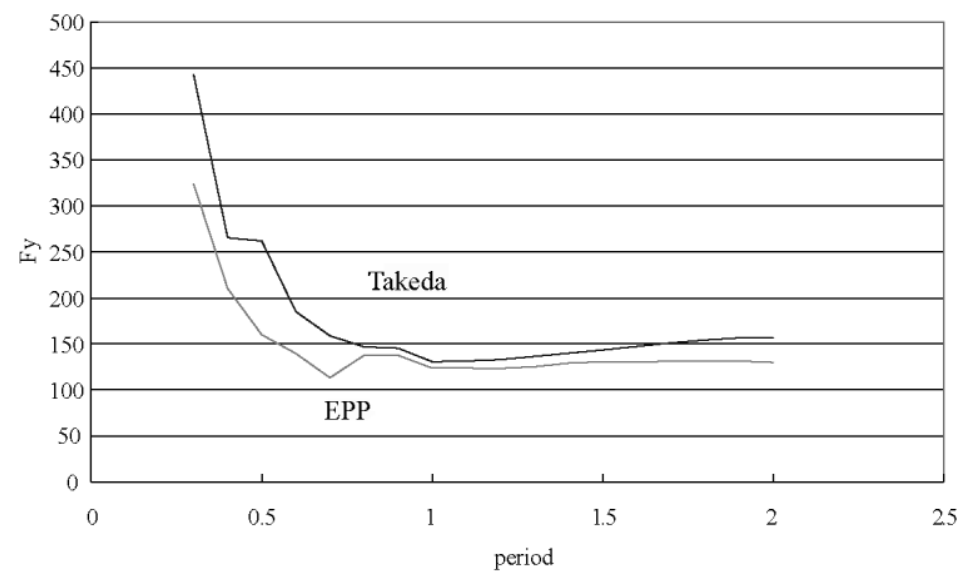

Figure 10. Comparison of the ductility spectrum (ductility ratio $\mu=4$ ) using the elastic-perfect-plastic (EPP) model and the proposed Takeda model

Figure 10 presents the spectrum of maximum yielding force (constant ductility spectrum) with a ductility ratio of $\mu=4$ from both the Takeda and the EPP models (the current code is derived based on the EPP model). It can be clearly found out that the EPP model has a lower maximum yielding force than the Takeda model. In general, the EPP model provides an non-conservative results. In the following sections discussion on the base shear coefficient using the proposed model with the codespecified value is made for different areas.

\section{Taipei Basin}

As shown in Figure 9(a) Taipei is a basin and there are over 40 free-field strong motion instruments in the basin. Strong motion data collected from stations in the central part of the basin is defined as the soft site condition (depth of soil deposit greater than $300 \mathrm{~m}$ ) in category 1 of Table 1 . Based on analysis of the inelastic response spectrum the base shear coefficient (BSC) was calculated using the proposed Takeda model. The input ground motion for the analysis are the data collected from stations in

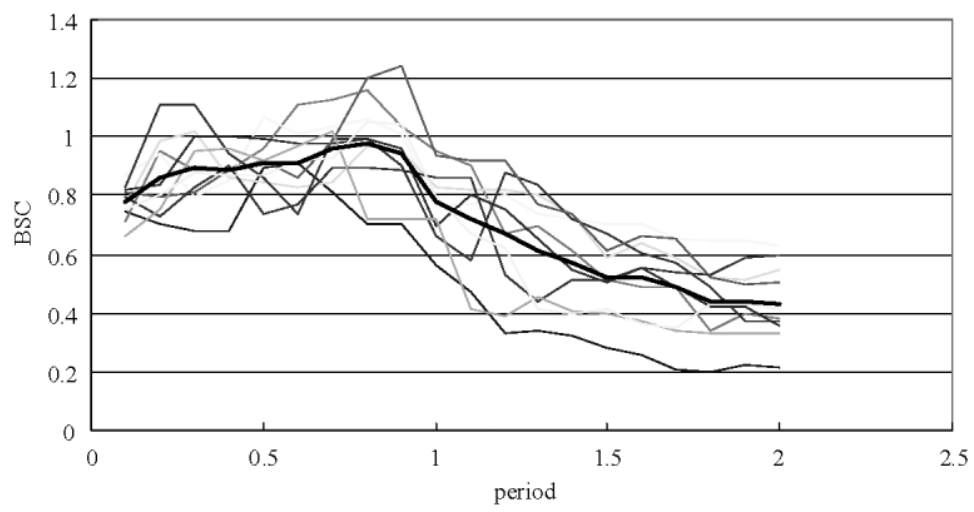

Figure 11. Plot of base shear coefficient (BSC) with respect to structural period using ground motion data from category 1 (see Table 1 ). The mean BSC is also shown (for ductility ratio $\mu=4$ ), as a dark solid line 


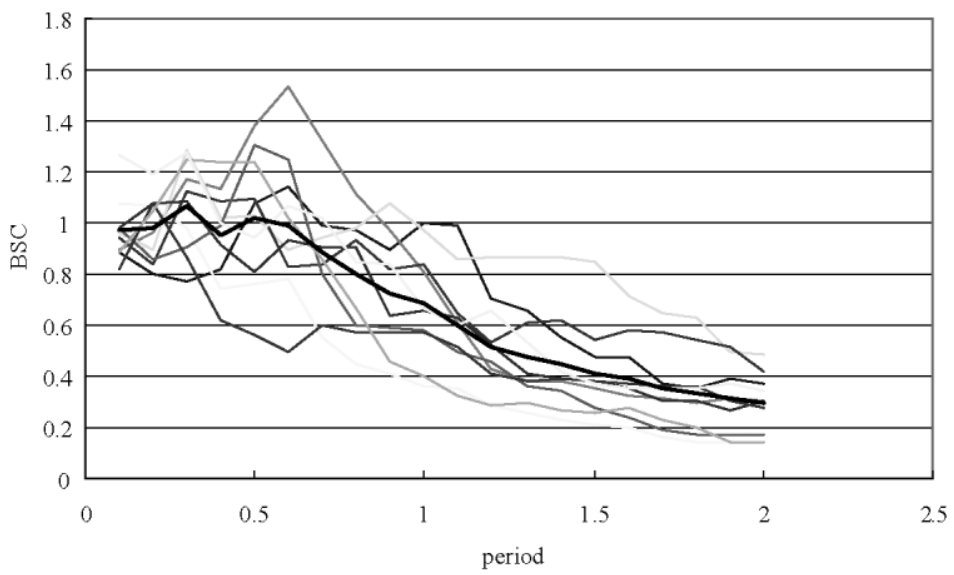

Figure 12. Plot of base shear coefficient (BSC) with respect to structural period using ground motion data from category 2 (see Table 1). The mean BSC is also shown (for ductility ratio $\mu=4$ ), as a dark solid line

(a)

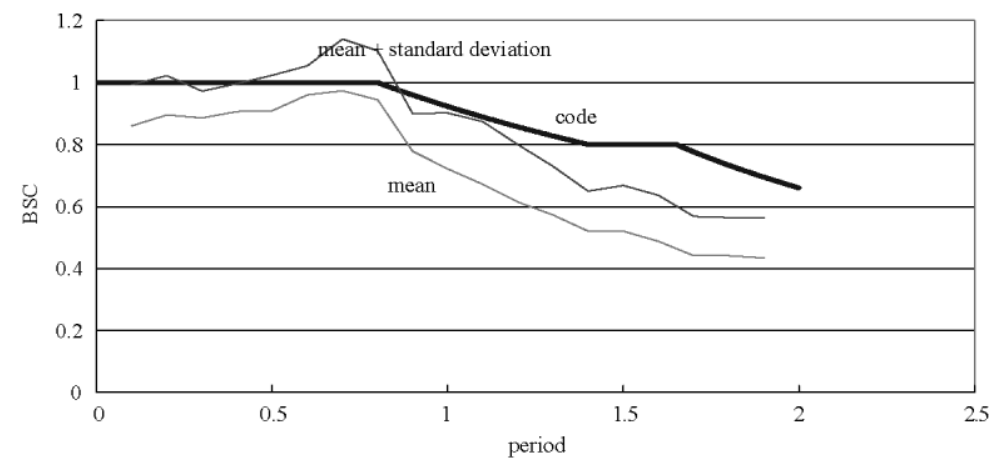

(b)

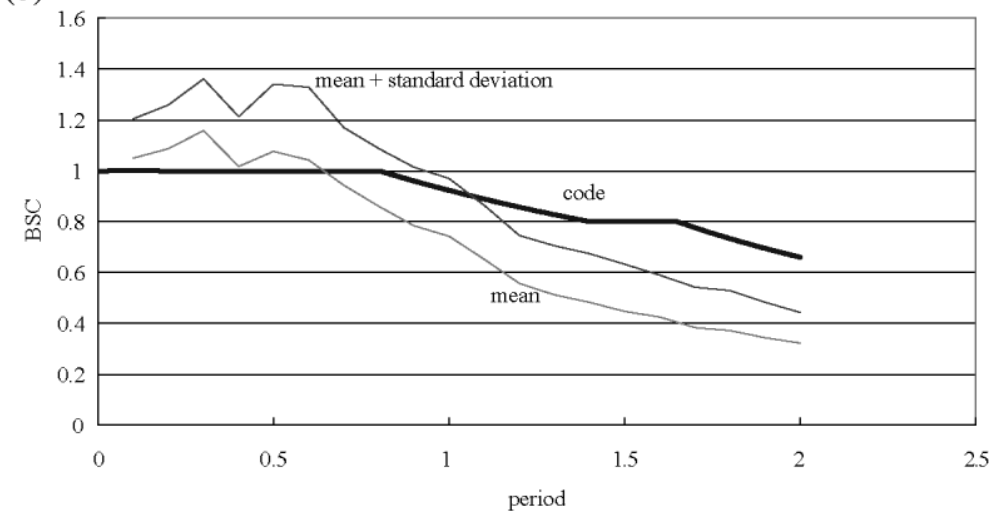

Figure 13. Plot of Taipei soil deposit mean and mean plus one standard deviation of the base shear coefficient (BSC) response spectrum for ductility ratio $\mu=4$ for (a) soft soil deposit and (b) hard soil deposit. Comparison with code-specified BSCs are also shown 
category 1 during the Chi-Chi earthquake. Figure 11 presents the BSC from data listed in category 1 of Table 1. The dark solid line represents the mean BSC. Different from the soft site condition in Taipei basin the BSCs of Taipei hard site condition are shown in Figure 12. Figure 12 presents all the BSCs from record ground motion at stations listed in Table 1 category 2 . In category 2 the hard site condition in the Taipei basin is defined with shear wave velocity less than $300 \mathrm{~m} \mathrm{~s}^{-1}$ (stations close to the boundary of the basin). The solid line presents the mean BSC. Comparison of the BSC provided by the seismic design code of Taipei Basin and the present study using Chi-Chi earthquake data is shown in Figure 13. Figure 13(a) presents the mean and mean plus one standard deviation BSC of Taipei soft soil deposit compared with the current code in Taipei basin. Figure 13(b) presents the mean and mean plus one standard deviation BSC of Taipei hard soil deposit compared with the current code in Taipei basin for a ductility ratio equal to 4 .

Both the normalized design spectrum and the reduction factor are site- and period-dependent functions. As an example, for bridges situated in the Taipei Basin, the code-specified design spectrum and reduction factor are defined by

$$
\begin{aligned}
& C= \begin{cases}1 \cdot 0, & T \geq 3 \cdot 3 \mathrm{~s} \\
3 \cdot 3 / T, & 1 \cdot 32 \mathrm{~s} \leq T \leq 3 \cdot 3 \mathrm{~s} \\
2 \cdot 5, & 0 \cdot 1 \mathrm{~s} \leq T \leq 1 \cdot 32 \mathrm{~s} \\
21 \cdot 43 T+0 \cdot 357, & 0 \cdot 03 \mathrm{~s} \leq T \leq 0 \cdot 1 \mathrm{~s} \\
1 \cdot 0, & T \leq 0 \cdot 030 \mathrm{~s}\end{cases} \\
& F_{u}= \begin{cases}R_{a}, & T \geq 1 \cdot 4 \mathrm{~s} \\
\sqrt{2 R_{a}-1}+\left[R_{a}-\sqrt{2 R_{a}-1}\right] \frac{(T-0 \cdot 8)}{0 \cdot 6}, & 0 \cdot 8 \mathrm{~s} \leq T \leq 1 \cdot 4 \mathrm{~s} \\
\sqrt{2 R_{a}-1}, & 0 \cdot 2 \mathrm{~s} \leq T \leq 0 \cdot 8 \mathrm{~s} \\
\sqrt{2 R_{a}-1}+\left[\sqrt{2 R_{a}-1}-1\right] \frac{(T-0 \cdot 2)}{0 \cdot 17}, & 0 \cdot 030 \mathrm{~s} \leq T \leq 0 \cdot 2 \mathrm{~s} \\
1 \cdot 0, & T \leq 0 \cdot 030 \mathrm{~s}\end{cases}
\end{aligned}
$$

The ratio of $C / F_{u}$ can be calculated by Equations (11) and (12) and is also drawn in Figure 13. This curve also represents the current code spectrum in the Taipei Basin. Based on the results shown in Figure 13, it is concluded that the original seismic design code for Taipei Basin can meet the seismic demand from soft site conditions of the Chi-Chi earthquake. However, the seismic design code for Taipei Basin cannot meet the seismic demand from hard site conditions of the Chi-Chi earthquake in the short period range. It means that in a basin one may need two or more reduction factors in the seismic design code to take care of the effect of the depth of soil deposit in the basin.

\section{Area in the Vicinity of Chelungpu Fault}

Another part of this study is to focus on the area near Chelungpu fault. When the Chi-Chi earthquake occured, the surface rupture extended from south to north for about $105 \mathrm{~km}$ in the central part of Taiwan which covered a lot of area of Tai-Chung and Chia-I counties. Based on the ground motion data collected from the Central Weather Bureau a lot of near-fault ground motion data were recorded. Table 2 presents the PGV/PGA ratio for stations around Tai-Chung county.

In Table 2, at stations Tcu052, Tcu068, Tcu075 and Tcu102, the PGV/PGA ratio are greater than 
EFFECTS OF HYSTERETIC MODEL ON SEISMIC DEMANDS

Table 2. Properties of selected near-fault ground motion record

\begin{tabular}{cccccc}
\hline Station number & $\begin{array}{c}\text { PGA } \\
\left(\mathrm{cms}^{-1} \mathrm{~s}^{-1}\right)\end{array}$ & $\begin{array}{c}\text { PGV } \\
\left(\mathrm{cm} / \mathrm{s}^{-1}\right)\end{array}$ & $\begin{array}{c}\text { Distance to the } \\
\text { fault }(\mathrm{km})\end{array}$ & $\begin{array}{c}\text { PGV/PGA } \\
\text { ratio }\end{array}$ & $\begin{array}{c}\text { Velocity pulse } \\
\text { duration }(\mathrm{s})\end{array}$ \\
\hline Tcu052 & $348 \cdot 7$ & $181 \cdot 8$ & $2 \cdot 34$ & $0 \cdot 521$ & $5 \cdot 54$ \\
Tcu068 & $501 \cdot 6$ & $280 \cdot 2$ & $0 \cdot 49$ & $0 \cdot 559$ & 3.85 \\
Tcu075 & $325 \cdot 3$ & $116 \cdot 5$ & $0 \cdot 43$ & $0 \cdot 358$ & 3.08 \\
Tcu102 & $298 \cdot 4$ & $86 \cdot 5$ & $0 \cdot 81$ & $0 \cdot 290$ & $7 \cdot 69$ \\
Tcu129 & $983 \cdot 6$ & $68 \cdot 1$ & $1 \cdot 65$ & $0 \cdot 069$ & negligible \\
Tcu065 & $774 \cdot 8$ & $132 \cdot 6$ & $0 \cdot 09$ & $0 \cdot 171$ & negligible \\
Tcu072 & $465 \cdot 5$ & $85 \cdot 5$ & $14 \cdot 6$ & $0 \cdot 184$ & negligible \\
Tcu084 & $989 \cdot 8$ & $115 \cdot 1$ & $20 \cdot 7$ & $0 \cdot 116$ & negligible \\
\hline
\end{tabular}

0.2. At stations Tcu129, Tcu065, Tcu072 and Tcu084 the PGV/PGA ratio is less than 0.2. A large PGV/PGA ratio indicates significant velocity pulse in the velocity wave form, and the effect of nearfault ground motion on the structure is more significant owing to the excitation of this pulse-like wave.

(a) $\mathrm{PGV} / \mathrm{PGA}>0.2$

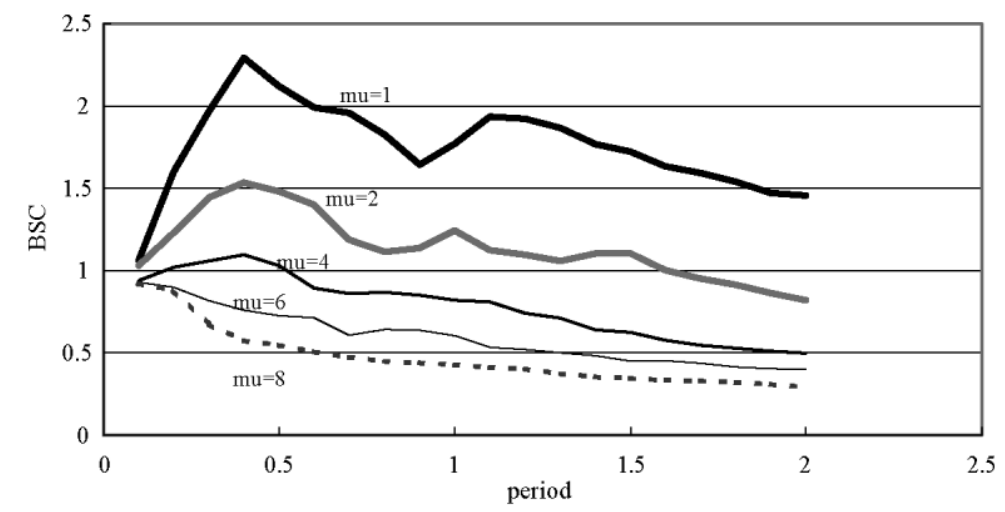

(b) $\mathrm{PGV} / \mathrm{PGA}<0.2$

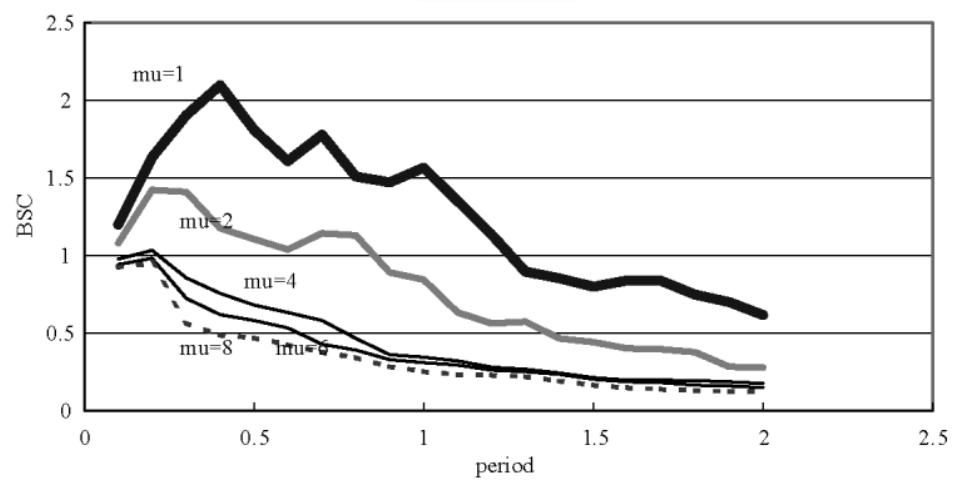

Figure 14. Plot of mean base shear coefficient (BSC) with repect to period for Taichung county using data with PGV/PGA (a) greater than $0 \cdot 2$ and (b) less than $0 \cdot 2$ 


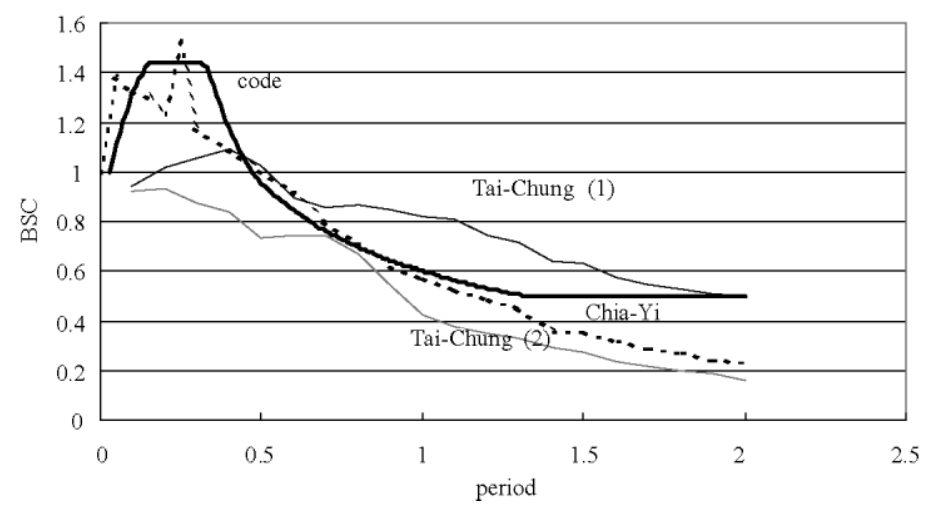

Figure 15. Comparison of the code-specified base shear coefficient (BSC) with the estimated BSC for the Taichung and Chai-I areas (for ductility $=4.0$ )

Figure 14 presents the mean BSC for $\mu=1,2,4,6$ and 8 in category 3 (Table 1). Figure 15 presents the comparison of the code-specified BSC response spectrum and the calculated BSC for Taichung (category 1), Taichung (category 2) and Chia-Yi.2 and (b) less than $0 \cdot 2$

Figure 15 illustrates that a higher PGV/PGA ratio will produce higher BSC values in the response spectrum. The BSC response curve presents a relatively high value when the structural period is small.

\section{SUMMARY AND CONCLUSIONS}

The goal of this research is to generate an inelastic response spectrum based on the experimental results of a reinforced-type structure. A bilinear Takeda (1970) model was found to fit best the data from the cyclic loading test. Verification of the model using earthquake excitation as input between pseudo-dynamic test results and the numerical simulation was also made. The Takeda model with model parameters that were identified from test data can predict the dynamic response of a bridge column with good accuracy.

With the proposed inelastic model the code-specified BSC was generated using data collected from the Chi-Chi earthquake. Comparison between the BSC from the present study and the code value was made for different areas of Taiwan. The code-specified BSC for Taipei Basin for soft soil deposits seems inadequate when the structure period is less than $0.8 \mathrm{~s}$, and the code-specified BSC for Taipei for hard soil deposits seems insufficient when the structure period is less than $1.1 \mathrm{~s}$. In Taichung county, the ratio of PGV/PGA governs the variation of the BSC response spectrum. When the PGV/ PGA ratio increases, the BSC value increases. In Taichung (category 1) the BSC response spectrum curve is higher than the code value when the structural period is greater than $0.4 \mathrm{~s}$. In the Chia-Yi plain, the BSC value is relatively higher when the structural period is smaller than $0.4 \mathrm{~s}$. It indicates that more detailed macro-zonation in the development of the code-specified BSC is necessary.

A major difficulty of this study was to simulate the reinforced column behaviour. The stiffnesses $k_{1}$, $k_{2}, k_{3}$ and $k_{4}$ were estimated from cyclic loading. The column behaves dramatically differently when it dynamic excitation loading was used. This phenomenon occurs because the cracking of concrete propagated easily in the static cyclic loading. The quality of concrete may govern this effect. 


\section{ACKNOWLEDGEMENTS}

This work was sponsored by grants from the National Science Council (grant number NSC89-2811E002-0001) and from the National Center for Research on Earthquake Engineering.

\section{REFERENCES}

Alavi B, Krawinkler H. 2000. Consideration of near fault ground motion effect in seismic design. 12th World Conference on Earthquake Engineering, Auckland, New Zealand.

Anderson JC, Bertero VV. 1987. Uncertainties inestablishing design earthquake, Journal of Structural Engineering, ASCE 113(8): 1709-1724.

Bertero VV, Mahin SA, Herrera RA. 1978. Aseismic design implications of San Fernando earthquake records. Earthquake Engineering and Structural Dynamics 6(1): 31-42.

Chai JF, Loh CH. 1999. Near-fault ground motion and its effect on civil structures. International Workshop on Mitigation of Seismic Effects on Transportation Structures. Taipei, Taiwan 70-81.

Iwan, WD. 1997. Drift spectrum: measure of demand for earthquake ground motions. Journal of Structural Engineering, ASCE 123(4): 397-404.

Kent DC, Park R. 1971. Flexural members with confined concrete. Journal of Structural Engineering, ASCE 97(ST7): 1969-1990.

Loh CH, Lee ZK, Wu TZ, Peng SY. 2000. Ground motion characteristics of the Chi-Chi earthquake of 21 September 1999. Earthquake Engineering and Structural Dynamics, 29: 876-897.

Makris N, Chang S. 2000. Effect of viscous, viscoelastic and friction damping on the response of seismic isolated structures. Earthquake Engineering and Structural Dynamics 29(1): 88-107.

Malhotra PK. 1999. Response of buildings to near-field pulse-like ground motions. Earthquake Engineering and Structural Dynamics 28: 1309-1326.

Priestley MJN, MacRae GA, Tao J. 1993. P-delta effect on single degree of freedom oscillators with degrading characteristics. Structural Systems Research Project, Report No. SSRP 93/05, Department of Applied and Engineering Sciences, University of California, San Diego, USA.

Takeda T, Sozen MA, Nilson NN. 1970. Reinforced concrete response to simulated earthquake. Journal of Structural Engineering, ASCE 96(12): 2557-2573.

Wan S. 1999. Analytical and Experimental Studies for Structures Subjected to Interplate and Intraplate Earthquake Considering the P- $\Delta$ effect. PhD dissertation, Civil Engineering, University of Memphis, TN. 